\title{
Review
}

J. Ginseng Res. Vol. 34, No. 2, 77-88 (2010)

DOI:10.5142/jgr.2010.34.2.077

\section{Korean Red Ginseng: Qualitative and Quantitative Benefits on Helicobacter pylori Infection}

\author{
Jun Won Chung, Yoon Jae Kim, So Jung Lee, and Ki Baik Hahm* \\ Department of Gastroenterology, Gachon Graduate School of Medicine Gil Medical Center, Incheon 405-760, Korea
}

\begin{abstract}
Ginseng has been reported to reduce the risk of cancer in diverse organs, including the lip, oral cavity, pharynx, larynx, esophagus, lung, liver, pancreas, ovary, colon, rectum, and stomach, as demonstrated in clinical and epidemiological studies. studies, base on which findings, Panax ginseng has been classified as a "non-organ-specific cancer preventive." However, the recent keen interest in traditional medicinal herbs has been frequently questioned, about exact mode of action and the use of panaceic compounds has been a prime issue discussed in terms of complementary and alternative medicine. Several in vitro and in vivo studies have shown the mitigating effects of Korean red ginseng on Helicobacter pylori ( $\mathrm{H}$. pylori)-associated atrophic changes and carcinogenesis; However, evidence-based medicine, consisting of large-scale or well designed clinical studies, is still warranted whether Korean red ginseng is to be recognized as an essential therapeutic strategy regarding a " $H$. pylori-associated gastric cancer preventive." Specifically, comprehensive clinical trials of Korean red ginseng are needed to demonstrate that mucosal regeneration in patients with atrophic gastritis is feasible using Korean red ginseng supplements after the eradication of H. pylori infection. Ginseng is a good example of a natural herb and its ubiquitous properties may include the reduction or delay of inflammation carcinogenesis. Korean red ginseng contains ample amounts of active ginsenosides and we have demonstrated their effects in in vitro and in vivo studies with positive outcomes. In this review, the quantitative and qualitative benefits of Korean red ginseng in the treatment of $H$. pylori infection are described.
\end{abstract}

Keywords: Korean red ginseng, Gastritis, Carcinogenesis, Rejuvenation, Cancer prevention, Halitosis, Eradication

\section{INTRODUCTION}

\section{An overview of Helicobacter pylori infection}

The discovery of the bacterium Helicobacter pylori (H. pylori), resident in the human stomach, as the causal agent of chronic disease including chronic gastritis, peptic ulcer diseases, and gastric cancer, was revolutionary in gastroenterology. Whereas the mouth and the colon were both known to host a large number of microorganisms, collectively referred to as the microbiome, the stomach was thought to be virtually sterile because its high acidity provides a very harsh environment for pathogens [1]. However, many species of bacteria are known reside in the stomach and that, among them, $H$. pylori seems to dominate [2]. Moreover, H. pylori was the first bacterium documented to behave as a carcinogen and it has been classified by the World Health Organization's International Agency for Research on Carcinogenesis (IARC) as a class I carcinogen [3-5]. While little doubt exists that $H$. pylori infection is a major factor in the pathogenesis of gastritis, gastroduodenal ulcer disease, and chronic atrophic gastritis (CAG), these diseases seems to originate from a complex interaction among the bacterium, the host, and the gastric environ-

\footnotetext{
(c) This is an Open Access article distributed under the terms of the Creative Commons Attribution Non-Commercial License (http://creativecommons.org/licenses/by-nc/3.0/) which permits unrestricted non-commercial use, distribution, and reproduction in any medium, provided the original work is properly cited.
}

Received 30 Mar. 2010, Revised 16 Apr. 2010, Accepted 19 Apr. 2010

*Corresponding author

E-mail: hahmkb@gachon.ac.kr

Tel: +82-32-899-6055, Fax: +82-32-899-6054 
ment. Accordingly, the eradication of $H$. pylori in asymptomatic individuals may not be the sole approach to sever these connections, nor is it clear why some people remain asymptomatic while in others, infection with the bacterium leads to the development of gastric cancer.

\section{H. pylori infection: pathogenic roles from gastritis to gastric cancer}

H. pylori colonize the stomach of more than half of the world's population, with infection playing a key role in the pathogenesis of many gastroduodenal diseases (Fig. 1a).

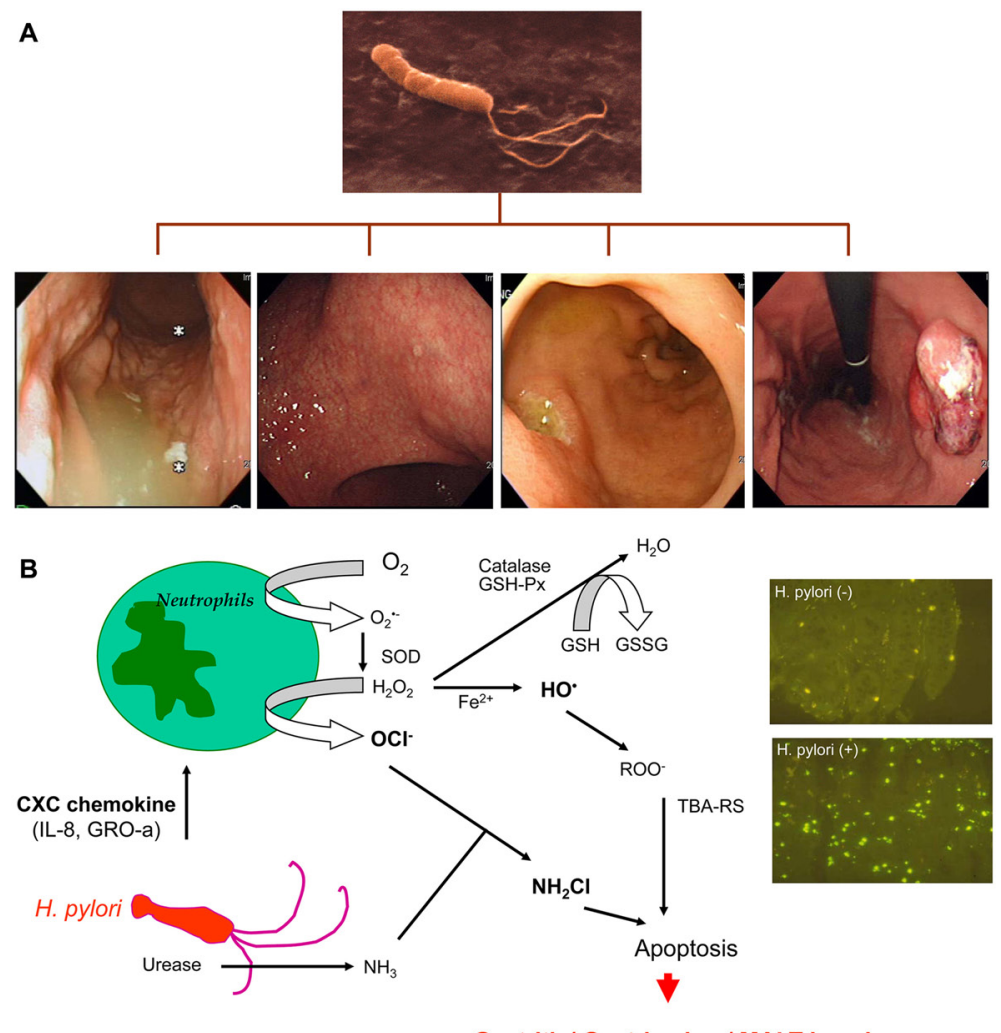

Gastritis/ Gastric ulcer/ MALT lymphoma

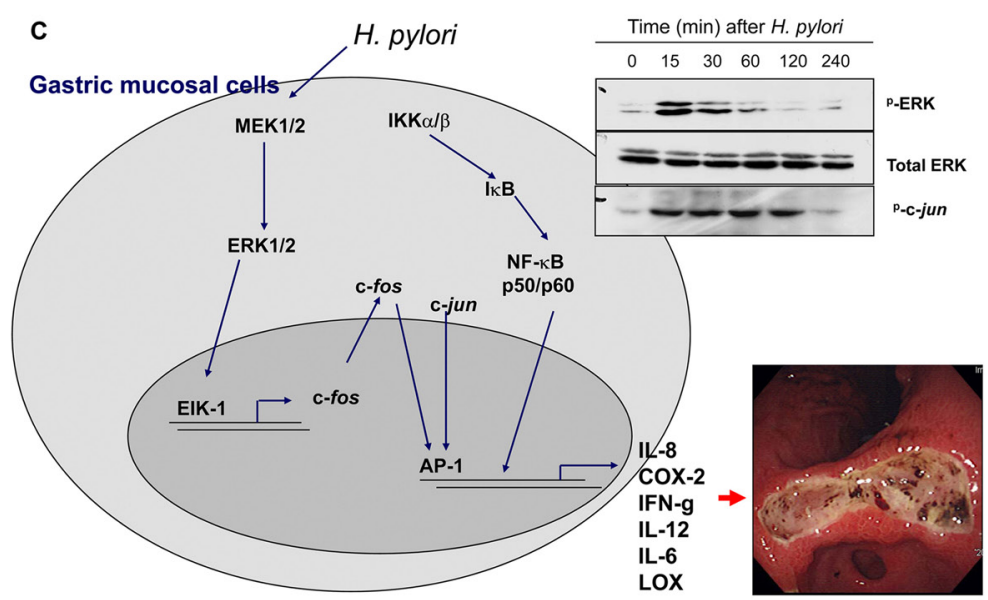

Fig. 1. Gastric diseases associated with Helicobacter pylori (H. pylori) infection. (a) H. pylori infection is associated with various gastric diseases, including acute and chronic gastritis, chronic atrophic gastritis, and gastric malignancies (mucosa-associated lymphoma tissue [MALT] lymphoma and adenocarcinoma). However, over $80 \%$ of adults infected with $\mathrm{H}$. pylori remain asymptomatic, such that treatment guidelines remain controversial. (b) Pathogenic mechanisms of $\mathrm{H}$. pylori-associated gastric mucosal damage include increased cytokine production, oxidative stress, and abnormally high rates of apoptosis, all of which contribute mechanistically to $H$. pylori-associated gastric mucosal injuries. (c) Signal transduction in response to cytokine generation after $H$. pylori infection. TBA-RS, thiobarbituric acid reactive substance; GRO-a, growth related oncogene-alpha; GSH, reduced glutathione; GSSG, oxidized glutathione; GSH-Px, glutathione peroxidase; NF-kB, nuclear factor-kappaB; IKK, inhibitory KB kinase; AP-1, activator protein-1; MEK1/2, MAP kinase kinase; ERK1/2, extracellular signal related kinase $1 / 2 ;$ ELK, ets oncogene family as ets related transcription factor. 
However, not all $H$. pylori strains have the same ability to cause gastric diseases, with host genetic background, environment, diet, hygiene, and cross talk between bacterial gene products and host cells as additional determining factors. Colonization of the gastric mucosa with H. pylori results in the development of chronic gastritis in most infected individuals, the clinical outcome of which is dependent on many variables, including $H$. pylori genotype, innate host physiology, host genetic predisposition, and environmental factors. However, a subset of these patients experience progression to complications such as peptic ulcer disease, gastric neoplasias, and extragastric disorders [6]. Since H. pylori eradication decreases the incidence of gastroduodenal ulcer and prevents its recurrence, CAG and gastric cancer have become the focus of great interest in terms of the feasibility of disease reversal or chemoprevention following eradication of the bacterium. A metaanalysis of studies on the association between $H$. pylori infection and CAG that were published until July 2007 was carried out by Weck and Brenner [7], with separate meta-analyses of studies defining CAG based on gastroscopy with biopsy, serum pepsinogen I (PG I) only, the PG I/pepsinogen II (PG II) ratio only, or a combination of the PG I and PG I/PG II ratios. The number of analyzed studies $(n)$ and the summary odds ratios (ORs) (95\% confidence intervals) were as follows: gastroscopy with biopsy: $n=34$, OR=6.4 (4.0-10.1); $\mathrm{PG}$ I only: $n=13, \mathrm{OR}=0.9(0.7-1.2)$; PG I/PG II ratio: $n=8$, $\mathrm{OR}=7.2$ (3.1-16.8); combination of PG I and PG I/PG II: $n=20, \mathrm{OR}=5.7$ (4.4-7.5). Studies with CAG definitions based on gastroscopy with biopsy or the PG I/PG II ratio (alone or in combination with the PG I) yielded similarly strong associations of $H$. pylori with CAG. These findings led to the conclusion that if the appropriate timing for intervention can be determined or an effective means of bioregulation of $H$. pylori-associated events identified, controlling $\mathrm{CAG}$ and gastric cancer will be possible. The importance of these capabilities is further underlined by the fact that, in addition to CAG, infection with $H$. pylori is associated with other extradigestive conditions, including respiratory disorders (chronic obstructive pulmonary disease, bronchiectasis, lung cancer, pulmonary tuberculosis, bronchial asthma), vascular disorders (ischemic heart disease, stroke, primary Raynaud phenomena, primary headache), autoimmune disorders (Sjögren syndrome, Henoch-Schonlein purpura, autoimmune thrombocytopenic purpura [ITP], autoimmune thyroiditis, Parkinson's disease, idiopathic chronic urticaria, rosacea, alopecia areata), and other conditions (iron deficiency anemia [IDA], growth retardations, liver cirrhosis) [8]. However, case studies, small patient series, and nonrandomized trials that have shown a beneficial effect of $H$. pylori eradication under different conditions are not convincing, and according to the Maastricht III criteria, the only conditions in which H. pylori eradication indicated are ITP and IDA [9].

\section{A cross-link between $\boldsymbol{H}$. pylori-associated CAG and gastric cancer}

The discovery of $H$. pylori as the causative pathogen of gastric cancer has raised hopes that the malignancy can be prevented through bacterial eradication, as epidemiological research and animal studies have confirmed the IARC (1994) classification of H. pylori as a definite carcinogen. This classification was based on theoretical considerations as well as the results of animal experiments showing that infection of $H$. pylori causes inflammatory-type infiltration, oxidative damage, and mutations of the gastric mucosa (Fig. 1b, c) [10-12]. In a resected gastric cancer specimen, intestinal metaplastic lesions were easily identified around cancer lesions. However, the reason why gastric cancer is not controlled after eradication of $H$. pylori can be explained by the sequence "CAG-intestinal metaplasiagastric cancer"; thus, only those patients who do not yet have malignant disease can be spared $H$. pyloriassociated carcinogenesis. Beyond this point, despite $H$. pylori eradication, inflammation in the stomach persists. Accordingly, amelioration of the gastric inflammation rather than simple eradication of the pathogen is generally accepted to be the key to cancer prevention [13]. This implies that chronic gastritis has a greater chance of leading to gastric cancer than infection by $H$. pylori alone. In this view, gastric cancer induced by $H$. pylori is actually the product of CAG and intestinal metaplasia, followed by dysplasia and, ultimately, intestinal malignancy $[14,15]$. Furthermore, in addition to gastric inflammation, genetic factors, toxicity of the pathogen, and environmental factors combine to promote $H$. pylori-induced gastric cancer subsequent to inflammation. Thus, the common denominator within this broad range of contributing factors and fundamental to the prevention of gastric cancer is the alleviation or attenuation of gastric inflammation.

\section{Non-antimicrobial Therapuetic Approaches to $H$. pylori Infection}

While the most effective therapeutic approach to the 
eradication of $H$. pylori is the combination of a proton pump inhibitor (PPI) with antibiotics, in $20-30 \%$ of patients, the method is not successful. In these patients, antibiotic resistance is a major factor affecting treatment outcome [16-18]. Therefore, non-antibiotic therapies, including phytomedicines, probiotics, and antioxidants, have been increasingly investigated as alternatives in the treatment of H. pylori [19-21]. In vitro experiments and in vivo nonhuman trials have examined the therapeutic potential of ginseng, wine, garlic, propolis, cranberry, green tea, probiotics, and antioxidants (Fig. 2a). In vivo human trials, most of which were aimed at determining the effects of supplements following $H$. pylo$r i$ eradication regimens, tested garlic, capsaicin, cinnamon, probiotics, Chinese herbal medicines, lactoferrin, and antioxidants including vitamin $\mathrm{C}$ and $\mathrm{E}$. In some cases, improved eradication rates or the reduction of the side effects of the various eradication regimens were documented. Kim et al. [22] conducted a randomized, open-label study to evaluate whether PPI-based 1-week triple therapy with adjunctive probiotic administration increased H. pylori eradication rates and reduced the adverse effects related to triple therapy. The addition of probiotics to triple therapy did not reduce side effects but did increase the eradication rate: $78.7 \%$ with eradication therapy alone versus $87.5 \%$ with eradication therapy plus 3 weeks of probiotics. Similar results were obtained in rather detailed clinical trials that examined H. pylori eradication through a non-antibiotic approach, such as vitamin $\mathrm{C}$, lactoferrin, and vitamin $\mathrm{E}$, and led to the conclusion that these compounds could improve the eradication rates obtained with anti-H. pylori therapy and

\section{A Non-microbial approach for $H$. pylori infection}
4. Licorice
5. Red pepper
6. Garlic
7. Ginger
8. Genistein
9. Red wines
10. Berries

1. Korean red ginseng

2. Green tea polyphenols

3. Probiotics (yoghurt)

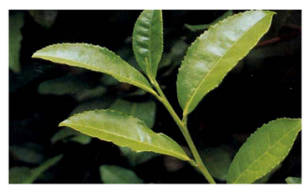

\section{B Chemical structure of ginseng saponins}

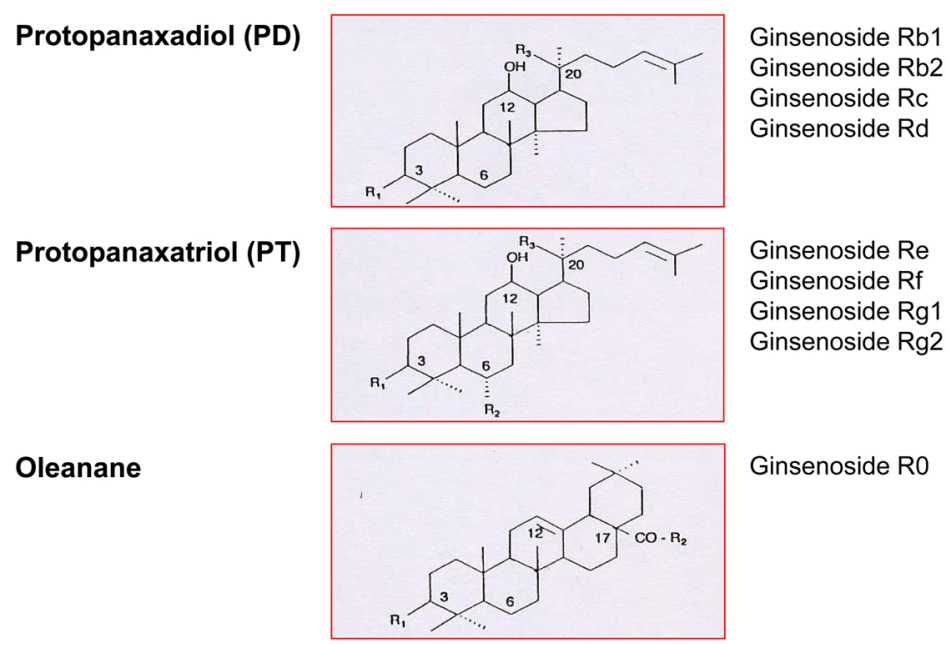

Fig. 2. Nonmicrobial approach to the treatment of Helicobacter pylori (H. pylori) infection. (a) Treatment guidelines for $H$. pylori eradication have yet to be established as no clear evidence exists that eradication of the bacterium results in cancer prevention, and gastric inflammation persists even after successful eradication. This has led to increased interest in nonmicrobial approaches to the treatment of $H$. pylori infection, including Korean red ginseng, probiotics, vitamins $\mathrm{C}$ and $\mathrm{E}$, garlic, ginger, and propolis. (b) protopanaxadiol and protopanaxatriol, the major components of ginseng saponins, may be the active agents in the therapeutic benefits of ginseng supplementation in $\mathrm{H}$. pylori infection. 
might be beneficial in patients with eradication failure $[23,24]$. However, results from a meta-analysis did not provide convincing evidence in favor of supplementary therapy. For example, Chuang et al. [25] and other investigators [26] found that in patients with metronidazolesusceptible $H$. pylori infection, the addition of vitamins may even lower the eradication rate of triple therapy. Therefore, whether the regular intake of dietary or dairy products might constitute a low-cost and safe alternative in the prevention of $H$. pylori infection remains to be examined in large-scale or prospective clinical trials.

\section{Korean red ginseng in the mitigation of $H$. pylori- associated gastric inflammation}

Several studies have demonstrated the antioxidant, antibacterial, and anti-inflammatory effects of ginseng [27-32]. Ginsenoside Rb1 was shown to inhibit lipopolysaccharide-induced expression of the proinflammatory cytokine tumor necrosis factor (TNF)- $\alpha$, while acidic polysaccharide from ginseng reportedly inhibits the adherence of $H$. pylori to human gastric epithelial cells (Fig. 2b). In addition to these antimicrobial actions, ginseng has distinctive inhibitory effects on the growth of several types of carcinoma cells. Therefore, can ginseng be used to treat $H$. pylori-infected gastric mucosal cells? Our group has documented that Korean red ginseng alleviates $H$. pylori-induced cytotoxicity [27] and mitigates oxidative stress-induced DNA mutation. In addition, Korean red ginseng decreased $H$. pylori-stimulated interleukin (IL)-8 expressions, supporting its use as a medicinal phytonutrient in $H$. pylori infection [21]. Subsequent investigations showed that Korean red ginseng decreases the levels of inflammatory mediators responsible for $\mathrm{CAG}$, intestinal metaplasia, and dysplasia. These anti-inflammatory actions were added to ginseng's cytoprotective or antimutagenic actions.

\section{Preventing precancerous atrophic gastritis: is it possible and then how?}

Can the atrophic mucosa characteristic of gastritis be reverted to a non-dysplastic condition either by removal of the bacteria through an eradication regimen or the clearance of gastric inflammation [33]? The answer is "yes, but not all." Although two recent large-scale, prospective studies, both performed in a population at high risk for gastric cancer, confirmed $H$. pylori infection as a definite risk factor for the development of gastric cancer $[3,34]$, the opposite premise, that the eradication of $H$. pylori infection is an appropriate target for the prevention of gastric cancer, has yet to be confirmed and remains controversial [35,36]. Three randomized, placebo-controlled trials performed in China and Columbia found no significant protective effect following H. pylori eradication [35-37], whereas three recently published Japanese studies $[10,13,38]$ reported that $H$. pylori eradication prevents the development of gastric cancer significantly, even in patients with precancerous gastric lesions. However, these observations did not address the possibility that earlier eradication therapy or other, similar types of intervention aimed at reducing gastric inflammation could be beneficial in high-risk populations [39]. Recently, Fukase et al. [40] published important results from their study in which, following endoscopic resection of early gastric cancer, a group of patients were randomly subjected to $H$. pylori eradication treatment, with monitoring at different time intervals. At 3 years, metachronous gastric cancer had developed in only 9 of 255 patients in the eradication group vs. 24 of 250 patients in the control group, leading the authors to conclude that prophylactic eradication of $H$. pylori in atrophic gastritis can substantially reduce gastric cancer rates. Nonetheless, the eradication of $H$. pylori infection might only be beneficial if carried out before gastric disease has passed the "point of no return"; however, with current endoscopy techniques or histopathology, discriminating whether a gastric premalignant lesion has indeed reached this stage is very difficult [12]. Instead, supplementary agents or continuing suppressive therapy to mitigate chronic gastric gastritis may well be a more effective approach to gastric cancer prevention (Fig. 3a). We and other investigators have shown that Korean red ginseng can contribute to preventing the progression of atrophic gastritis and to mucosal reversion in non-atrophic gastritis. In the following, we present several examples of the qualitative advantages conferred by the administration of Korean red ginseng to patients with $H$. pylori infection, including anti-halitosis, anti-inflammation, and chemopreventive effects.

\section{QUALITATIVE ADVANTAGES OF KOREAN RED GIN- SENG IN H. pylori INFECTION}

\section{Korean red ginseng in the treatment of halitosis: evidences from in vitro observations to clinical applications}

Halitosis is a general term describing a range of unpleasant or putrefactive odors emanating from the oral cavity $[41,42]$. It is a rather common symptom that can be troublesome to patients socially, decreasing selfconfidence or limiting social interactions. Due to it's 
A

Qualitative advantage of Korea red ginseng

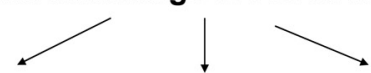

rejuvenation of atrophic gastritis, halitosis improvement, attenuated inflammation

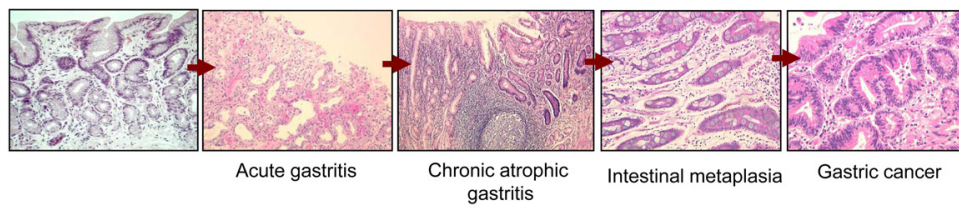

Augmented eradication rate of $H$. pylori

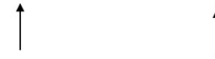

Quantitative advantage of Korea red ginseng

B Homeostasis maintenance with Korea red ginseng

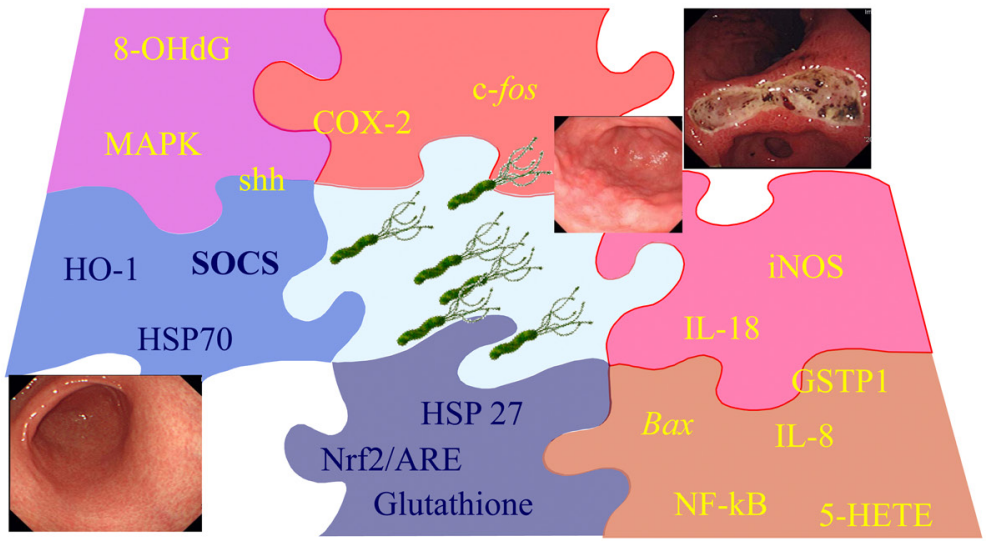

Fig. 3. Korean red ginseng, phytoceuticals in the treatment of Helicobacter pylori (H. pylori) infection. (a) The anti-oxidative, anti-inflammatory, and antimutagenic actions of Korean red ginseng may explain its ability to improve gastric inflammation, with potential rejuvenation of the mucosa in atrophic gastritis and the improvement of symptoms such as halitosis. In addition, Korean red ginseng significantly augmented the eradication rates achieved with the current triple therapy. (b) The maintenance of gastric homeostasis is essential in H. pylori infection, as studies have suggested that the treatment benefits of $H$. pylori eradication alone are limited to the prevention of gastroduodenal ulcer. MAPK, mitogen activated protein kinase; shh, sonic hedgehog; COX-2, cyclooxygenase-2; HSP70, heat shock protein 70; HO-1, heme oxidase-1; 5-HETE, 5-monohydroxyeicosahexanoic acid; nrf-2, NF-E2-related factor 2.

vague pathogenic basis and the low level of medical concerning, only a few satisfying solution exists for halitosis [43]. When severe, a patient's physician or dentist is likely to advise patients to undergo gastrointestinal examination, as gastrointestinal diseases have been suggested to cause halitosis [44], although critical evidence for a causative relationship is lacking except in the case of $H$. pylori infection [45]. Lee et al. [28] showed that $H$. pylori produces volatile sulfur compounds (VSCs) in the presence of cysteine in culture media, and Katsinelos et al. [46] reported that eradication of $H$. pylori in patients with functional dyspepsia leads to sustained resolution of halitosis during longterm follow-up. We found that Korean red ginseng can resolve halitosis through either regulation of the genes responsible for VSC synthesis or direct inhibition of $H$. pylori infection. The evidence is as follows: $H$. pylori increased the levels of cystathionine $\gamma$-lyase (CSE) and cystathionine $\beta$-synthase (CBS) mRNA, which encode inflammatory cytokines that promote VSC synthesis, and of the inflammatory mediators IL- $1 \beta$, IL-8, and IL6; Korean red ginseng significantly attenuated CSE and CBS mRNA production concomitant with decreased expression of the respective proteins; significant reductions in halimeter ppb levels $(<50)$ were obtained after H. pylori eradication and red ginseng supplementation [47]. Thus, halitosis appears to be mechanistically associated with $H$. pylori infection, and Korean red ginseng supplementation following a successful eradication regimen could alleviate troublesome halitosis. In previous publications [48,49], we showed that VSCs in gastric juices were significantly correlated with halitosis and that halitosis could be symptomatic of mucosal damage, including gastric erosions or ulcers. Those studies dem- 
onstrated that Korean red ginseng supplementation after H. pylori eradication augmented bacterial eradication and conferred significant protection against $\mathrm{H}$. pylori-induced mucosal damage [27], thus providing both quantitative and qualitative advantages in $\mathrm{H}$. pylori-associated gastric mucosal injuries, including the relief of halitosis.

\section{Limitation of CAG progression with Korean red ginseng}

As Korean red ginseng has been reported to confer significant protection against $H$. pylori-induced cytotoxicity and DNA damage in vitro, we designed a study to assess the efficacy of red ginseng treatment in patients with $H$. pylori-associated chronic gastritis [49]. The 84 patients with $H$. pylori-associated chronic gastritis were randomly divided into two groups. Of the 42 patients in the placebo control group and 42 in the red ginseng group, 34 and 36, respectively, completed the protocol. All patients received 1 week of triple therapy for the eradication of $H$. pylori and then 10 weeks of either a capsule composed of flour for the placebo group, or red ginseng for the treatment group. All patients underwent an endoscopic examination of gastritis, scored by a visual analog scale and a test for the detection of H. pylori. DNA damage was assessed using a Comet assay, and the degree of oxidative DNA damage by immunohistochemical staining of 8-hydroxydeoxyguanosine (8-OHdG). Apoptosis was quantified by TUNEL staining. An analysis of gastritis based on the Updated Sydney System showed significant improvement in the red ginseng group with respect to in neutrophil infiltration $(p=0.008)$, CAG severity $(p<0.05)$, and even intestinal metaplasia $(p=0.005)$. An attenuation of $8-\mathrm{OHdG}$ immunohistostaining, DNA damage, and apoptosis $(p<0.001)$ after treatment was seen more frequently in the red ginseng group than in the placebo group These findings recommend the clinical usefulness of Korean red ginseng supplementation in patients with $H$. pyloriassociated chronic gastritis (Fig. 3a,b).

\section{Korean red ginseng in the prevention of gastric cancer}

Carcinogenesis is a long and multi-step process that includes initiation, promotion, and progression as a consequence of an imbalance between cell proliferation and cell death. The complex inflammatory response involving the epithelial layer and mesenchymal tissues is accompanied by genetic and epigenetic events, which, by conferring distinct advantages in cell growth, lead to the progressive conversion of normal cells into cancer cells [11,50,51]. A wide array of chronic inflammatory conditions predisposes susceptible cells to neoplastic transformation $[52,53]$. Inflammatory stimuli include chemicals and foreign bodies (e.g., asbestos, fiber, silica particles, catheters, alcohol, bile acids, gastric acids, gallbladder stones, and ultraviolet light) and infectious organisms (e.g., H. pylori, hepatitis $\mathrm{B}$ and $\mathrm{C}$ viruses, Epstein-Barr virus, herpes virus, human papilloma virus, and human immunodeficiency virus) $[54,55]$. Inflammatory cells (neutrophils, monocytes, macrophages, eosinophils, dendritic cells, mast cells, and lymphocytes) are recruited after cell or tissue damage or in response to infection and contribute to the onset and progression of cancer [56]. In general, the longer the duration of inflammation, the higher the risk of cancer will be. Moreover, once a tumor develops, the tumor cells continuously stimulate macrophages and other inflammatory cells to promote tumor progression through the production of pro-inflammatory cytokines, including TNF- $\alpha$, interleukin (IL)-1 $\beta$, IL-6, IL-8, interferon- $\gamma$, Murine Double Minute 2 (MDM2), p53, and angiogenic factors. Also, an imbalance between reactive oxygen species (ROS)-generating enzymes and antioxidant defense mechanisms is involved, leading to oxidative stress, and an activation of $\mathrm{NF}-\kappa \mathrm{B}$, inducible nitric oxide synthase (iNOS), cyclooxygenase (COX)2 , proteinases, and oncogenes. The trophic nature of the tumor microenvironment facilitates angiogenesis, breakdown of the extracellular matrix, and tumor cell motility [57,58].

Inflammation therefore represents an important therapeutic target for cancer prevention and cure, and numerous chemopreventive agents with inflammationattenuating activity have been studied, including ginseng, curcumin, retinoids, vitamin E, silimarin, aspirin, celecoxib, plant polyphenols, and PPIs [59,60]. A PubMed search for "cancer" and "Panax ginseng (P. ginseng)" yielded over 400 articles, reflecting the widespread interest in $P$. ginseng in mitigating carcinogenesis through anti-inflammatory, antioxidant, and anti-apoptotic mechanisms. These publications addressed ginseng-mediated induction of differentiation, specifically, the repair or reverse transformation of hepatoma, melanoma, and teratocarcinoma cells into more differentiated cells, and its effects in reducing chemical carcinogens; inhibiting the development of chemically induced (methyl-N-nitrosourea and N-ethyl$\mathrm{N}$-nitrosourea) rat mammary adenocarcinoma; and mitigating inflammatory carcinogenesis. The antioxidant effects of ginseng include reductions in COX-2, iNOS, 
$\mathrm{NF}-\kappa \mathrm{B}$, and lipid peroxidation, and the scavenging of ROS. The active components of ginsenoside were shown to induce apoptosis and inhibit proliferation as well as cell cycle progression, all of which have been implicated as chemopreventive mechanisms. With the exception of one study to the contrary, ginsenosides were shown to block metastasis and tumorigenesis and to promote immunomodulation [61].

Ginseng has been frequently studied postoperatively and was shown to improve recovery from surgery or illness. Other effects of ginseng include the relief of multidrug resistance (MDR), in the form of enhanced chemosensitizing effects and reduced MDR-related efflux pump activity, and dual angiogenic effects, i.e., anti-angiogenic activity in carcinogenesis and angiogenic activity in the context of healing $[30,61,62]$. In a representational investigation that provided evidence of the anti-carcinogenic properties of ginseng, Yun [63] carried out a human epidemiology study and a well designed animal study, the results of which were published in Lancet Oncology (2001). Yun analyzed the effects of ginseng consumption on the risk of cancer by interviewing 905 paired patients and controls matched by age, sex, and date of admission to the Korean Cancer Center Hospital, Seoul, Korea. A significant decrease in the frequency of cancer cases among those with the highest ginseng intake was found for men $(p<0.0001)$ and women $(p<0.05)$. These results strong support for the cancer-preventing effects of ginseng.

\section{QUANTITATIVE ADVANTAGE OF KOREAN RED GINSENG IN H. pylori INFECTION}

Given the major role played by $H$. pylori in the pathogenesis of chronic gastritis, atrophic gastritis, gastric and duodenal ulcers, and gastric malignancies, including adenocarcinoma and mucosa-associated lymphoma tissue lymphoma (Fig. 1a) [37], great emphasis has been placed on eradication of the bacterium in infected patients especially in light of the substantial advantages shown for this therapeutic strategy. Thus far, the only exception is in gastric cancer prevention, in which the benefits remain uncertain [36]. According to the Maastricht consensus, the first-line therapy for $H$. pylori eradication is the combination of a PPI or the antiulcer agent ranitidine bismuth citrate and clarithromycin plus either amoxicillin or metronidazole $[16,18]$. The eradication rates obtained with this approach range from $75 \%$ to $98 \%$ with a median of $80 \%$. However, this implies that treatment will fail in up to $20 \%$ of patients, and the rate is likely to be even higher in areas with a high prevalence of resistant $H$. pylori strains, as in Korea [64]. The recommended second-line therapy is a quadruple regimen composed of tetracycline, metronidazole, bismuth salts, and a PPI. However, the efficacy of these first- and second-line regimens is limited by poor compliance due to the lengthy treatment duration, the number and dose of prescribed drugs, and the mild but unpleasant side effects such as diarrhea, nausea, vomiting, abdominal bloating, and pain. Premature interruption of treatment for any of these reasons increases the likelihood of subsequent bacterial antibiotic resistance [17,65]. Gastroenterologists and microbiologists continue to search for new therapies as the extent of $H$. pylori-related disease has become increasingly evident and have made attempts to relieve the physiologic and pharmacoeconomic burden to patients needing second-line therapy. To increase the efficacy of first-line therapy, several clinical trials have examined extending treatment duration to more than 1 week, the use of higher doses of PPIs, and the introduction of new antibiotics such as quinolone. Other approaches include the use of first-line quadruple therapy and the addition of probiotics, vitamin $\mathrm{C}$, bovine lactoferrin, and other nonantibiotic supplements, including ginseng, wine, garlic, honey, and cranberry [19,66,67].

Based on our previous studies, as discussed extensively in the preceding sections, we carried out a prospective clinical study to confirm whether supplementation of Korean red ginseng indeed increases the likelihood of successful H. pylori eradication. Among 76 subjects, 45 patients were enrolled in the eradication-alone group and 31 patients in the eradication plus Korean red ginseng group. Participants were assigned randomly based on patient registration number. All patients had $H$. pylori-associated CAG and the baseline characteristics of the two groups were similar. According to an intention to treat analysis, the eradication rates were $77.4 \%$ (24 of 31 ) in the Korean red ginseng group compared to $51.0 \%$ (26 of 45 ) in the eradication alone group. While this difference was not significant, a perprotocol analysis showed that successful eradication of H. pylori was achieved in 24 of 26 patients $(92.3 \%)$ in the Korean red ginseng group, which was significantly higher than in the eradication alone group (26 of 38, $69.4 \% ; p<0.05$ ). No case of noncompliance occurred in the Korean red ginseng group, whereas one patient in the eradication alone group took the prescribed medications for 3 days only. One patient stopped Korean red ginseng supplementation due to epigastric 
pain and bloating, whereas four patients in the eradication alone group discontinued medication due to diarrhea in two patients, dizziness and nausea in one patient, and bitter aftertaste and epigastric soreness in one patient. Four patients were lost to follow-up in the Korean red ginseng group and one patient in the eradication alone group [68].

In a previous published trial, we assessed the eradication rate under the same protocol (i.e., eradication alone vs. eradication plus 10 weeks of Korean red ginseng supplementation), although over a different time course $[47,49]$. By combining the data from the current and the previous trial to determine the overall efficacy of Korean red ginseng supplementation on the $H$. pylori eradication rate, we found that a 10 -week course of Korean red ginseng (Jeongkwanjang red ginseng capsule, 2.7 g/day; Korea Ginseng Cooperation, Daejeon, Korea) supplementation significantly augmented eradication rates (eradication alone group 75 of $102,73.5 \%$ vs. eradication plus Korean red ginseng group 82 of $90,91.1 \% ; p<0.005)$. We thus conclude that supplementation of Korean red ginseng can provide quantitative and qualitative benefits in the treatment of $H$. pylori infection, especially in populations with notoriously high incidences of $H$. pylori-associated gastric malignancy. The prevalence of $H$. pylori infection is believed to decrease as socioeconomic status improves [69], with one exception: the prevalence of $H$. pylori infection and associated gastric cancer remains high in Korea and Japan. Two nationwide prevalence surveys performed in 1998 and 2005 among asymptomatic Korean adults found a prevalence of $H$. pylori infection of $66.9 \%$ and $59.5 \%$, respectively [70], which was not due to an increase in H. pylori infection but to the frequent failure of eradication. Korean red ginseng supplementation will therefore provide dual benefits, by offering qualitative and quantitative improvements to patients with $H$. pylori infection.

\section{ACKNOWLEDGEMENTS}

The study was granted from the Korean Society of Ginseng funded by Korea Ginseng Corporation. The authors would like to give sincere thanks to Ms. SJ Lee, and Ms. JY Park, RN (Gachon Graduate School of Medicine) for their contributions to clinical study.

\section{REFERENCES}

1. Dorer MS, Talarico S, Salama NR. Helicobacter pylori's unconventional role in health and disease. PLoS Pathog 2009;5:e1000544.

2. McNamara D, El-Omar E. Helicobacter pylori infection and the pathogenesis of gastric cancer: a paradigm for host-bacterial interactions. Dig Liver Dis 2008;40:504509.

3. Uemura N, Okamoto S, Yamamoto S, Matsumura N, Yamaguchi S, Yamakido M, Taniyama K, Sasaki N, Schlemper RJ. Helicobacter pylori infection and the development of gastric cancer. N Engl J Med 2001;345:784789.

4. Suerbaum S, Michetti P. Helicobacter pylori infection. N Engl J Med 2002;347:1175-1186.

5. Correa P, Houghton J. Carcinogenesis of Helicobacter pylori. Gastroenterology 2007;133:659-672.

6. Suzuki H, Hibi T, Marshall BJ. Helicobacter pylori: present status and future prospects in Japan. J Gastroenterol 2007;42:1-15.

7. Weck MN, Brenner H. Association of Helicobacter pylori infection with chronic atrophic gastritis: Meta-analyses according to type of disease definition. Int $\mathrm{J}$ Cancer 2008;123:874-881.

8. Suzuki H, Marshall BJ, Hibi T. Overview: Helicobacter pylori and extragastric disease. Int J Hematol 2006;84:291300.

9. Prelipcean CC, Mihai C, Gogalniceanu P, Mitrica D, Drug VL, Stanciu C. Extragastric manifestations of Helicobacter pylori infection. Rev Med Chir Soc Med Nat Iasi 2007; 111:575-583.

10. Take S, Mizuno M, Ishiki K, Nagahara Y, Yoshida T, Yokota K, Oguma K, Okada H, Shiratori Y. The effect of eradicating Helicobacter pylori on the development of gastric cancer in patients with peptic ulcer disease. Am J Gastroenterol 2005;100:1037-1042.

11. Aggarwal BB, Shishodia S, Sandur SK, Pandey MK, Sethi G. Inflammation and cancer: how hot is the link? Biochem Pharmacol 2006;72:1605-1621.

12. Lee DH, Hahm KB. Inflammatory cytokine gene polymorphisms and gastric cancer. J Gastroenterol Hepatol 2008;23:1470-1472.

13. Kato M, Asaka M, Nakamura T, Azuma T, Tomita E, Kamoshida T, Sato K, Inaba T, Shirasaka D, Okamoto S, et al. Helicobacter pylori eradication prevents the development of gastric cancer - results of a long-term retrospective study in Japan. Aliment Pharmacol Ther Symp Series 2006;24:203-206.

14. Sung JJ, Lin SR, Ching JY, Zhou LY, To KF, Wang RT, Leung WK, Ng EK, Lau JY, Lee YT, et al. Atrophy and intestinal metaplasia one year after cure of $H$. pylori infection: a prospective, randomized study. Gastroenterol- 
ogy 2000;119:7-14.

15. Park S, Kim WS, Choi UJ, Han SU, Kim YS, Kim YB, Chung MH, Nam KT, Kim DY, Cho SW, et al. Amelioration of oxidative stress with ensuing inflammation contributes to chemoprevention of $H$. pylori-associated gastric carcinogenesis. Antioxid Redox Signal 2004;6:549560.

16. Malfertheiner P, Megraud F, O'Morain C, Hungin AP, Jones R, Axon A, Graham DY, Tytgat G; European Helicobacter Pylori Study Group (EHPSG). Current concepts in the management of Helicobacter pylori infection--the Maastricht 2-2000 Consensus Report. Aliment Pharmacol Ther 2002;16:167-180.

17. McLoughlin R, Racz I, Buckley M, O’Connor HJ, O'Morain C. Therapy of Helicobacter pylori. Helicobacter 2004;9 Suppl 1:42-48.

18. Malfertheiner P, Megraud F, O’Morain C, Bazzoli F, ElOmar E, Graham D, Hunt R, Rokkas T, Vakil N, Kuipers EJ. Current concepts in the management of Helicobacter pylori infection: the Maastricht III Consensus Report. Gut 2007;56:772-781.

19. Gaby AR. Helicobacter pylori eradication: are there alternatives to antibiotics? Altern Med Rev 2001;6:355-366.

20. Carson CF, Riley TV. Non-antibiotic therapies for infectious diseases. Commun Dis Intell 2003;27 Suppl:S143S146.

21. Lee SY, Shin YW, Hahm KB. Phytoceuticals: mighty but ignored weapons against Helicobacter pylori infection. J Dig Dis 2008;9:129-139.

22. Kim MN, Kim N, Lee SH, Park YS, Hwang JH, Kim JW, Jeong SH, Lee DH, Kim JS, Jung HC, et al. The effects of probiotics on PPI-triple therapy for Helicobacter pylori eradication. Helicobacter 2008;13:261-268.

23. Sachdeva A, Nagpal J. Meta-analysis: efficacy of bovine lactoferrin in Helicobacter pylori eradication. Aliment Pharmacol Ther 2009;29:720-730.

24. Sezikli M, Cetinkaya ZA, Sezikli H, Guzelbulut F, Tiftikci A, Ince AT, Gokden Y, Yasar B, Atalay S, Kurdas OO. Oxidative stress in Helicobacter pylori infection: does supplementation with vitamins $\mathrm{C}$ and $\mathrm{E}$ increase the eradication rate? Helicobacter 2009; 14:280-285.

25. Chuang CH, Sheu BS, Huang AH, Yang HB, Wu JJ. Vitamin $\mathrm{C}$ and $\mathrm{E}$ supplements to lansoprazole-amoxicillinmetronidazole triple therapy may reduce the eradication rate of metronidazole-susceptible Helicobacter pylori infection. Helicobacter 2002;7:310-316.

26. Gotteland M, Brunser O, Cruchet S. Systematic review: are probiotics useful in controlling gastric colonization by Helicobacter pylori? Aliment Pharmacol Ther 2006;23:1077-1086.
27. Park S, Yeo M, Jin JH, Lee KM, Jung JY, Choue R, Cho SW, Hahm KB. Rescue of Helicobacter pylori-induced cytotoxicity by red ginseng. Dig Dis Sci 2005;50:12181227.

28. Lee H, Kho HS, Chung JW, Chung SC, Kim YK. Volatile sulfur compounds produced by Helicobacter pylori. J Clin Gastroenterol 2006;40:421-426.

29. Lee WM, Kim SD, Kim KS, Song YB, Kwak YS, Cho JY, Park HJ, Oh JW, Rhee MH. Protopanaxadiol modulates LPS-induced inflammatory activity in murine macrophage RAW264.7 cells. J Ginseng Res 2006;30:181187.

30. Kim EH, Park JD, Pyo SN, Rhee DK. Effects of nonsaponin red ginseng components on multi-drug resistance. J Ginseng Res 2007;31:74-78.

31. Park S, Yeo M, Jin JH, Lee KM, Kim SS, Choi SY, Hahm KB. Inhibitory activities and attenuated expressions of 5-LOX with red ginseng in Helicobacter pylori-infected gastric epithelial cells. Dig Dis Sci 2007;52:973-982.

32. Joo HK, Lee SK, Kim HS, Song YJ, Kang G, Park JB, Lee KH, Cho EJ, Lee JH, Seong IW, et al. Korean red ginseng extract inhibits tumor necrosis factor-alpha-induced monocyte adhesion in the human endothelial cells. J Ginseng Res 2008;32:244-249.

33. Chung JW, Hahm KB. Rejuvenation of atrophic gastritis in the elderly. J Gastroenterol Hepatol 2010;25:434-435.

34. You WC, Zhang L, Gail MH, Chang YS, Liu WD, Ma JL, Li JY, Jin ML, Hu YR, Yang CS, et al. Gastric dysplasia and gastric cancer: Helicobacter pylori, serum vitamin C, and other risk factors. J Natl Cancer Inst 2000;92:16071612.

35. Leung WK, Lin SR, Ching JY, To KF, Ng EK, Chan FK, Lau JY, Sung JJ. Factors predicting progression of gastric intestinal metaplasia: results of a randomised trial on $\mathrm{He}$ licobacter pylori eradication. Gut 2004;53:1244-1249.

36. Wong BC, Lam SK, Wong WM, Chen JS, Zheng TT, Feng RE, Lai KC, Hu WH, Yuen ST, Leung SY, et al. Helicobacter pylori eradication to prevent gastric cancer in a high-risk region of China: a randomized controlled trial. JAMA 2004;291:187-194.

37. Mera R, Fontham ET, Bravo LE, Bravo JC, Piazuelo $\mathrm{MB}$, Camargo MC, Correa P. Long term follow up of patients treated for Helicobacter pylori infection. Gut 2005;54:1536-1540.

38. Takenaka R, Okada H, Kato J, Makidono C, Hori S, Kawahara Y, Miyoshi M, Yumoto E, Imagawa A, Toyokawa $\mathrm{T}$, et al. Helicobacter pylori eradication reduced the incidence of gastric cancer, especially of the intestinal type. Aliment Pharmacol Ther 2007;25:805-812.

39. Kabir S. Effect of Helicobacter pylori eradication on inci- 
dence of gastric cancer in human and animal models: underlying biochemical and molecular events. Helicobacter 2009;14:159-171.

40. Fukase K, Kato M, Kikuchi S, Inoue K, Uemura N, Okamoto S, Terao S, Amagai K, Hayashi S, Asaka M, et al. Effect of eradication of Helicobacter pylori on incidence of metachronous gastric carcinoma after endoscopic resection of early gastric cancer: an open-label, randomised controlled trial. Lancet 2008;372:392-397.

41. Tangerman A. Halitosis in medicine: a review. Int Dent J 2002;52 Suppl 3:201-206

42. Porter SR, Scully C. Oral malodour (halitosis). BMJ 2006;333:632-635.

43. Feller L, Blignaut E. Halitosis: a review. SADJ 2005;60:17-19.

44. Hoshi K, Yamano Y, Mitsunaga A, Shimizu S, Kagawa J, Ogiuchi H. Gastrointestinal diseases and halitosis: association of gastric Helicobacter pylori infection. Int Dent $\mathbf{J}$ 2002;52 Suppl 3:207-211.

45. Tiomny E, Arber N, Moshkowitz M, Peled Y, Gilat T. Halitosis and Helicobacter pylori. A possible link? J Clin Gastroenterol 1992;15:236-237.

46. Katsinelos P, Tziomalos K, Chatzimavroudis G, Vasiliadis T, Katsinelos T, Pilpilidis I, Triantafillidis I, Paroutoglou G, Papaziogas B. Eradication therapy in Helicobacter pylori-positive patients with halitosis: long-term outcome. Med Princ Pract 2007;16:119-123.

47. Lee JS, Kwon KA, Jung HS, Kim JH, Hahm KB. Korea red ginseng on Helicobacter pylori-induced halitosis: newer therapeutic strategy and a plausible mechanism. Digestion 2009;80:192-199.

48. Yoo SH, Jung HS, Sohn WS, Kim BH, Ku BH, Kim YS, Park SW, Hahm KB. Volatile sulfur compounds as a predictor for esophagogastroduodenal mucosal injury. Gut Liver 2008;2:113-118.

49. Kim DK, Lee JA, Kim YB, Lee KM, Hahm KB. A randomized controlled trial assessing Korea red ginseng treatment of Helicobacter pylori-associated chronic gastritis. Korean J Med 2007;72:20-28.

50. Lu H, Ouyang W, Huang C. Inflammation, a key event in cancer development. Mol Cancer Res 2006;4:221-233.

51. Federico A, Morgillo F, Tuccillo C, Ciardiello F, Loguercio C. Chronic inflammation and oxidative stress in human carcinogenesis. Int J Cancer 2007;121:2381-2386.

52. Moss SF, Blaser MJ. Mechanisms of disease: Inflammation and the origins of cancer. Nat Clin Pract Oncol 2005;2:90-97.

53. Ono M. Molecular links between tumor angiogenesis and inflammation: inflammatory stimuli of macrophages and cancer cells as targets for therapeutic strategy. Cancer Sci
2008;99:1501-1506.

54. Balkwill F, Mantovani A. Inflammation and cancer: back to Virchow? Lancet 2001;357:539-545.

55. Bode AM, Dong Z. Cancer prevention research - then and now. Nat Rev Cancer 2009;9:508-516.

56. Ohshima H, Tazawa H, Sylla BS, Sawa T. Prevention of human cancer by modulation of chronic inflammatory processes. Mutat Res 2005;591:110-122.

57. Pollard JW. Tumour-educated macrophages promote tumour progression and metastasis. Nat Rev Cancer 2004;4:71-78.

58. Hussain SP, Hofseth LJ, Harris CC. Radical causes of cancer. Nat Rev Cancer 2003;3:276-285.

59. Suzuki M, Suzuki H, Hibi T. Proton pump inhibitors and gastritis. J Clin Biochem Nutr 2008;42:71-75.

60. Nakajima N, Ito Y, Yokoyama K, Uno A, Kinukawa N, Nemoto N, Moriyama M. The Expression of Murine Double Minute 2 (MDM2) on Helicobacter pylori-infected intestinal metaplasia and gastric cancer. J Clin Biochem Nutr 2009;44:196-202.

61. Odashima S, Ohta T, Kohno H, Matsuda T, Kitagawa I, Abe H, Arichi S. Control of phenotypic expression of cultured B16 melanoma cells by plant glycosides. Cancer Res 1985;45:2781-2784.

62. Keum YS, Park KK, Lee JM, Chun KS, Park JH, Lee SK, Kwon H, Surh YJ. Antioxidant and anti-tumor promoting activities of the methanol extract of heat-processed ginseng. Cancer Lett 2000;150:41-48.

63 . Yun TK. Panax ginseng--a non-organ-specific cancer preventive? Lancet Oncol 2001;2:49-55.

64. Lee JH, Cheon JH, Park MJ, Kim N, Lee DH, Kim JM, Kim JS, Jung HC, Song IS. The trend of eradication rates of second-line quadruple therapy containing metronidazole for Helicobacter pylori infection: an analysis of recent eight years. Korean J Gastroenterol 2005;46:94-98.

65. Houben MH, van de Beek D, Hensen EF, Craen AJ, Rauws EA, Tytgat GN. A systematic review of Helicobacter pylori eradication therapy--the impact of antimicrobial resistance on eradication rates. Aliment Pharmacol Ther 1999; 13:1047-1055.

66. Gisbert JP, Pajares JM. Review article: Helicobacter pylori "rescue" regimen when proton pump inhibitorbased triple therapies fail. Aliment Pharmacol Ther 2002;16:1047-1057.

67. Zojaji H, Talaie R, Mirsattari D, Haghazali M, Molaei M, Mohsenian N, Derakhshan F, Zali MR. The efficacy of Helicobacter pylori eradication regimen with and without vitamin C supplementation. Dig Liver Dis 2009;41:644647.

68. Lee SJ, Park JY, Choi KS, Ock CY, Hong KS, Kim YJ, 
Chung JW, Hahm KB. Efficacy of Korean red ginseng supplementation on eradication rate and gastric volatile sulfur compound levels after Helicobacter pylori eradiction therapy. J Ginseng Res 2010;34:122-131.

69. Pounder RE, Ng D. The prevalence of Helicobacter pylori infection in different countries. Aliment Pharmacol
Ther 1995;9 Suppl 2:33-39.

70. Yim JY, Kim N, Choi SH, Kim YS, Cho KR, Kim SS, Seo GS, Kim HU, Baik GH, Sin CS, et al. Seroprevalence of Helicobacter pylori in South Korea. Helicobacter 2007;12:333-340. 